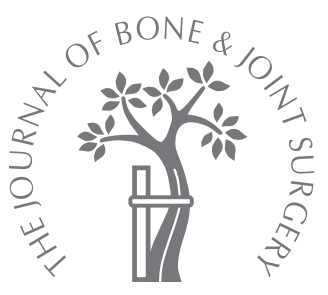

R. H. M. ten

Broeke,

A. Alves,

A. Baumann,

J. J. C. Arts,

R. G. T. Geesink

From Maastricht

University Medical

Centre, Maastricht,

The Netherlands

In. H. M. ten Broeke, MD,

Orthopaedic Surgeon

J. J. C. Arts, PhD, Senior

Research Scientist

n. G. T. Geesink, MD, PhD

Professor Emeritus of

Orthopaedic Surgery

Department of Orthopaedic

Surgery

Maastricht University Medical

Centre, P. O. Box 5800, 6202AZ

Maastricht, The Netherlands.

A. Alves, MS, MS,

Pathologist and Study Director

Biomatech - Namsa Company,

Z. I. de L'Islon, 115 Rue Pasteur,

38670 Chasse-sur-Rhône,

France.

A. Baumann, Dipl. Ing.,

Director Innovation

Management

DOT GmbH, Charles-Darwin-

Ring 1a, D-18059 Rostock,

Germany.

Correspondence should be sent to Mr R. H. M. ten Broeke;

e-mail: r.ten.broeke@mumc.nl

(C)2011 British Editorial Society of Bone and Joint Surgery doi:10.1302/0301-620X.93B6. $24986 \$ 2.00$

$J$ Bone Joint Surg [Br] 2011;93-B:760-8.

Received 10 April 2010;

Accepted after revision 19

January 2011

\title{
Bone reaction to a biomimetic third- generation hydroxyapatite coating and new surface treatment for the Symax hip stem
}

Four uncemented Symax hip stems were extracted at three weeks and nine, 13 and 32 months, respectively, for reasons other than loosening. The reasons for implant removal were infection in two cases, recurrent dislocation in one and acetabular fracture in one. They were analysed to assess the effect and behaviour of an electrochemically deposited, completely resorbable biomimetic BONIT-hydroxyapatite (HA) coating (proximal part) and a DOTIZE surface treatment (distal part) using qualitative histology, quantitative histomorphometry and scanning electron microscopy (SEM). Early and direct bone-implant bonding with signs of active remodelling of bone and the HA coating were demonstrated by histology and SEM. No loose BONIT-HA particles or delamination of the coating were observed, and there was no inflammation or fibrous interposition at the interface.

Histomorphometry showed bone-implant contact varying between $26.5 \%$ at three weeks and $\mathbf{8 3 . 5 \%}$ at 13 months at the HA-coated implant surface. The bone density in the area of investigation was between $24.6 \%$ at three weeks and $41.1 \%$ at 32 months. The DOTIZE surface treatment of the distal part of the stem completely prevented tissue and bone apposition in all cases, thereby optimising proximal stress transfer.

The overall features of this implant, in terms of geometry and surface texture, suggest a mechanically stable design with a highly active biomimetic coating, resulting in rapid and extensive osseo-integration, exclusively in the metaphyseal part of the stem. Early remodelling of the HA coating does not seem to have a detrimental effect on short-term bone-implant coupling. There were no adverse effects identified from either the BONIT-HA coating or the DOTIZE surface treatment.

Since the introduction of cementless designs for total hip replacement (THR), the greatest step forward to true osseo-integration was calcium phosphate coatings for early bone apposition and biological fixation. Of these, hydroxyapatite (HA) is the most used and documented, both in basic research ${ }^{1-3}$ and in short- $^{-4-6}$ and long-term clinical experience. ${ }^{7,8}$ Implant retrievals in humans have shown consistent evidence of osseo-integration. ${ }^{9-11}$

The majority of the experience is associated with HA-coated implants using a firstgeneration plasma-spray technique, ${ }^{12}$ which is an established technology, both cost-effective and reproducible. This so-called 'line-of-sight' coating technique has the disadvantage of coating only the outermost layer of the implant surface, like a paint spray, which occludes the deeper layers of the more open threedimensional surface textures. This will result in bone apposition to the superficial comparatively thicker coating, but not to the underlying titanium, thereby creating an extra interface.
This unfavourable situation may exist for a long time, owing to the relatively insoluble, highly crystalline plasma-spray coating. Although there is no clear evidence that loss of plasma-sprayed coating affects the long-term performance of the implant, there is concern about deterioration of the bone-implant contact after degradation of the coating. ${ }^{10,13,14}$ Another issue is that degradation of plasmaspray HA coatings might generate 'third-body wear' particles, which could initiate the differentiation of macrophages into osteoclasts, eventually leading to deterioration of the boneimplant bond and loosening. ${ }^{15-17}$

Newer techniques, such as electrophoretic deposition, ion beam-assisted deposition and solution deposition can uniformly coat the superficial and deeper layers of implants with porous surfaces, resulting in a deeper bioactive layer applied onto and particularly into the more open surface structure of the implant. This provides a larger surface area for osteoconduction and creates a deeper and tighter 


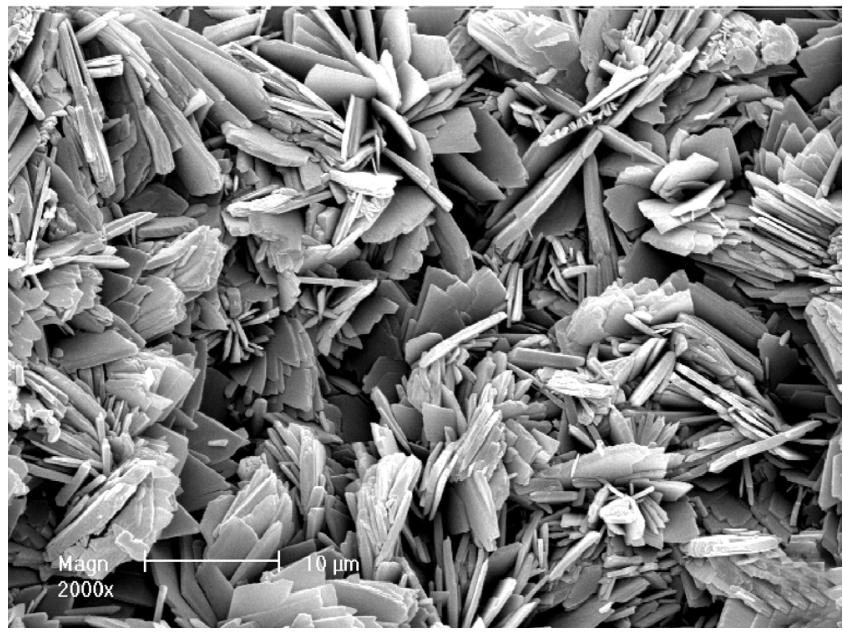

Fig. 1a

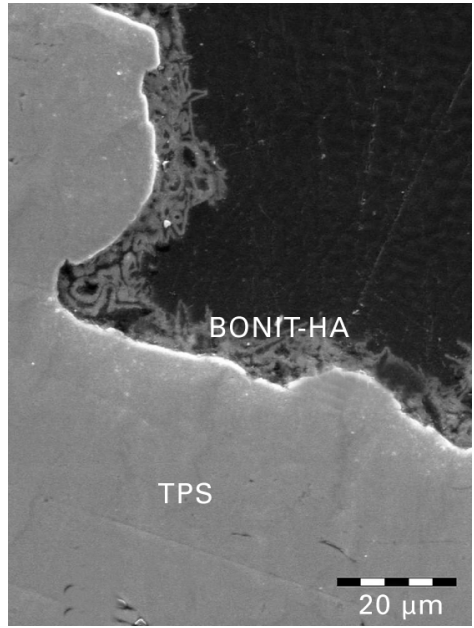

Fig. 1b

Details of the coating of the Symax stem surface (titanium plasma spray (TPS) with BONIT-HA coating). Figure 1a - scanning electron microscope (SEM) photograph showing the typical efflorescent needle-like structure of BONIT-HA crystals on the irregular threedimensional open surface texture of the high-porosity titanium plasma-sprayed layer ( $\times 2000$ magnification). Figure $1 \mathrm{~b}-\mathrm{SEM}$ photograph of a cross-section of an implant showing the TPS layer and BONIT-HA coating; maximum thickness of $10 \mu \mathrm{m}$ of BONIT-HA coating and deep penetration into the TPS layer (×500 magnification).

anchorage to bone. The so called 'biomimetic' (nature-like) coatings such as BONIT-HA (DOT GmbH, Rostock, Germany) are based on the deposition and growth of microcrystalline calcium phosphate molecules from supersaturated calcifying solutions (simulated body fluids). ${ }^{18-22}$ Usually these coatings are much thinner $(2 \mu \mathrm{m}$ to $20 \mu \mathrm{m}$ ) than the $50 \mu \mathrm{m}$ to $200 \mu \mathrm{m}$ thick plasma-sprayed coatings. This diminishes the risk of fatigue fracture and delamination, which were early concerns with the thicker and more brittle coatings. The thinner coatings are more evenly and controllably deposited and can be better regulated in terms of purity and crystallinity, and hence resorbability because of better control of the physiochemical circumstances $(\mathrm{pH}$, temperature, saturation and calcium phosphate composition of the simulated body fluid) under which they are produced. ${ }^{23}$ The advantage of lowtemperature processing is a more predictable and controlled environment for the deposition of the coating. This results in more crystallographically consistent coatings without creating undesired calcium phosphates than with the high temperatures (up to $20000^{\circ} \mathrm{C}$ ) of plasma spraying. Although there are pre-clinical studies with biomimetic coatings showing promising outcomes, ${ }^{21,22,24}$ there is little clinical experience.

In this study, four retrieved uncemented Symax stems were analysed by qualitative histology, quantitative histomorphometry and scanning electron microscopy (SEM). Special attention was devoted to local tolerance, potential adverse effects, bioactivity and durability of their proximal BONIT-HA coatings, thereby recording their capacity for direct implant-bone bonding, the rate of remodelling and degradation of the coating and the possible consequences of this process for the bone coupling of the underlying hip stem. The effect of BONIT-HA applied proximally was related to DOTIZE treatment (DOT GmbH) on the distal part of the stem, a process of anionic oxidation, which was developed to diminish bone apposition and osseointegration, in order to optimise stress transfer from the prosthesis to the bone in the proximal HA-coated area.

\section{Materials and Methods}

The design of the Symax stem (Stryker, Montreux, Switzerland) is based on close geometrical analysis of human femoral anatomy through conventional radiography and CT. It aims at optimal fit and fill with loading of the proximal femur, thereby allowing more natural stress distribution and less stress shielding. Furthermore, a uniform interface stress pattern is pursued for the maintenance of optimal interface bonding. The achievement of both goals was confirmed pre-clinically by finite element analysis.

The stem is forged from Ti6Al4V alloy. It had a proximal plasma-sprayed commercially pure titanium coating (complying with the ASTM International specifications of ASTM F67 and ASTM F1580) ${ }^{25}$ to enhance initial fixation, and a biomimetic electrochemically deposited BONIT-HA coating (ASTM F1088-87, ASTM F1609-95 and International Organization for Standardization (ISO) 13779-2,25,26 DOT GmbH; Fig. 1). Distally, it is treated with the DOTIZE surface process (DOT GmbH), an electrolytic conversion of titanium surfaces in which the thin native oxide film is replaced by a thicker, oxidised conversion layer that reduces protein adsorption and hence distal bone apposition and osseo-integration. ${ }^{27,28}$ The roughened plasmasprayed titanium surface has an open porosity of $20 \%$ to $40 \%$ and an average pore size between $50 \mu \mathrm{m}$ and $200 \mu \mathrm{m}$. The $\mathrm{Ca} / \mathrm{P}$ ratio of the BONIT-HA coating is 1.6 (SD 0.1 ). It is described as 'nanocrystalline' $\mathrm{HA}^{29}$ and the X-ray diffraction and infra-red spectroscopy patterns demonstrate a 
Table I. Details of patients who generated the four retrieved Symax hip stems

\begin{tabular}{|c|c|c|c|c|}
\hline Case & 1 & 2 & 3 & 4 \\
\hline Age (yrs) at $\mathrm{THR}^{*}$ & 74 & 78 & 64 & 61 \\
\hline Gender & $\mathrm{F}$ & $\mathrm{M}$ & $\mathrm{M}$ & $M$ \\
\hline Weight (kg) & 64 & 81 & 78 & 84 \\
\hline Height (m) & 1.65 & 1.71 & 1.70 & 1.74 \\
\hline Diagnosis at primary THR & $\mathrm{OA}^{\dagger}$ & OA & $\mathrm{OA}$ & $\mathrm{OA}$ \\
\hline Previous hip surgery & None & None & None & None \\
\hline \multirow[t]{2}{*}{ Activity level with THR } & \multirow[t]{2}{*}{ Not rehabilitated after THR } & \multirow[t]{2}{*}{ Semi-sedentary due to comorbidity } & Normal activity & Light work \\
\hline & & & Light work & Occasional sports \\
\hline Reason for extraction & Acetabular fracture after THR & $\begin{array}{l}\text { Deep infection (Staphylococcus } \\
\text { aureus) }\end{array}$ & $\begin{array}{l}\text { Deep infection } \\
\text { (Staph. aureus) }\end{array}$ & $\begin{array}{l}\text { Recurrent dislocation } \\
\text { (acetabular component } \\
\text { malpos/offset) }\end{array}$ \\
\hline Clinical signs of loosening & Not applicable & None & None & None \\
\hline Radiological signs of loosening & Not applicable & None & None & None \\
\hline $\begin{array}{l}\text { Surgeon's comments on } \\
\text { fixation quality }\end{array}$ & $\begin{array}{l}\text { Press fit; not yet } \\
\text { osseointegrated }\end{array}$ & Well fixed $\left(\mathrm{ETO}^{\ddagger}\right.$ necessary) & (ETO necessary) & (ETO necessary) \\
\hline
\end{tabular}

composition and crystalline structure similar to that of bone. ${ }^{24}$ The initial coating, which is deposited electrochemically at room temperature, is a composite of brushite $\left(\mathrm{CaHPO}_{4} \cdot 2 \mathrm{H}_{2} \mathrm{O}\right)$ converted to $\mathrm{HA}$ by $\mathrm{NaOH}$ treatment. ${ }^{22,24}$ It has a fine crystalline structure, where $\mathrm{CaP}$ crystals are fixed on the titanium plasma-sprayed surface in the shape of platelets and pins of $15 \mu \mathrm{m}$ to $20 \mu \mathrm{m}$ in length (Fig. 1$)^{30}$ and a high porosity of $60 \%$. This creates an exceptional capillary effect, which enables complete moistening by bone marrow with early adhesion and proliferation of osteoblast-like cells. $^{22,24}$ The adhesion strength of the BONIT-HA coating on the titanium plasma-sprayed coating, which should not be less than $15 \mathrm{MPa}$ according to ISO $13779-4,{ }^{26}$ is 61.29 MPa (SD 6.26) (ASTM F1147-99). ${ }^{25}$

Between November 2004 and August 2006, four uncemented femoral stems were extracted for different reasons (Table I). After retrieval, they were treated according to the same protocol. There were no clinical or radiological signs of loosening at the time of extraction. Cases 1 to 3 were implanted in another hospital and case 4 in our department. The reason for removal in case 1 was an acetabular fracture. During the repair, the femoral component was taken out for better exposure of the acetabulum. In cases 2 and 3 there was a deep infection with Staphylococcus aureus resistant to several debridements and antibiotic treatments. During revision of case 4 for recurrent dislocation in a non-compliant patient, as well as improving the anteversion of the acetabular component, it was decided to replace the stem with a design with more offset.

The specimens were fixed in $3.7 \%$ to $4.0 \%$ formalin, buffered with zinc sulphate acetate at pH 5.6 to 5.8 and transported to an independent institute (Biomatech, Chasse-sur-Rhône, France). On the day of receipt, they were stored in $10 \%$ buffered formalin $(\mathrm{pH} 7.2$ to 7.4$)$. After fixation, cross-sections approximately $1.5 \mathrm{~cm}$ thick according to the Gruen zones ${ }^{31}$ were made, using the EXAKT microcutting system (Apparatebau GmbH \& Co., Norderstedt, Germany). Each segment was dehydrated in increasing concentrations of ethanol, cleared in xylene and embedded in polymethylmethacrylate (PMMA) resin.

One to five cross-sections approximately $30 \mu \mathrm{m}$ thick were prepared in Gruen zones $1 \mathrm{~A}$ to $7 \mathrm{~A}, 1 \mathrm{~B}$ to $7 \mathrm{~B}, 1 \mathrm{C}$ to $7 \mathrm{~B}$, 2 to 6 and 3 to 5 . The sections were obtained by a microcutting and grinding technique adapted from Donath and Breuner $^{32}$ and stained with a modified Paragon stain ${ }^{33}$ for qualitative histology and quantitative histomorphometry. For the qualitative microscopic analysis, we used a Nikon microscope (Eclipse E600; Nikon France, Champigny-surMarne, France) fitted with $\times 5, \times 10, \times 20$ and $\times 40$ objectives, coupled to a digital camera (DN 100; Nikon France). For the quantitative analysis, the sections were evaluated using a Zeiss microscope (Axioskop; Carl Zeiss France S. A. S., Le Pecq, France) fitted with $\times 5, \times 10, \times 20$ and $\times 40$ objectives and equipped with a colour image analysing system (SAMBA; SAMBA Technologies, Meylan, France).

The quantitative histomorphometric evaluation of the surrounding bone (bone to implant contact and bone area density) was performed on seven standardised areas around the stem sections ( $1 \mathrm{~A}$ to $7 \mathrm{~A}, 1 \mathrm{~B}$ to $7 \mathrm{~B}$ and $1 \mathrm{C}$ to $7 \mathrm{~B}$ ) and on four areas around the distal sections 2 to 6 and 3 to 5 (29 areas in total). The surfaces of the individual areas of investigation varied from $10 \mathrm{~mm}^{2}$ to $12 \mathrm{~mm}^{2}$ and were located at the tissue-implant interface. Within the area of investigation the surface taken by bone was divided by the surface of the entire area in order to calculate the relative bone density in the vicinity of the implant. The length of the 
implant's interface having direct bone contact was divided by the length of the entire interface within the area of investigation in order to provide the percentage of the implant covered by bone (bone-implant contact). The means and SDs were calculated for each section and for the whole metaphyseal segment of the stem.

Scanning electron microscopy (SEM). For SEM the blocks from the proximal part of the stem were dehydrated in acetone solution, submitted to critical point for dessication (optimal dehydration for optimised SEM pictures) and sputtered with gold palladium before observation. The analysis was conducted with a HITACHI S800 scanning electron microscope (Hitachi High-Technologies Europe $\mathrm{GmbH}$, Krefeld, Germany) set at $15 \mathrm{KeV}$. Any significant event was recorded and photographed.

\section{Results}

Qualitative histology. The retrieved specimens showed successive changes during prospective peri-prosthetic bone remodelling and the effects of coating loss on bone-implant coupling. Although in case 1 there was bone over only a small surface of the explant owing to the short period of implantation, in all other cases there was extensive and qualitatively sound bone-implant bonding, defined as a continuum of mineral from the implant to the bone matrix without a fibrous tissue interface. ${ }^{10}$ Histological examination consistently showed trabecular bridges from the surrounding bone to the implant surface. These bridges were characterised by mature lamellar bone with osteoblasts and osteocytes, except for case 1, which showed woven bone (Fig. 2a). Active remodelling of bone was frequently seen, with osteoid lines as a sign of new bone formation (Figs $2 b$ and $2 c$ ).

In all specimens the BONIT-HA coating had completely disappeared, reflecting rapid degradation of this thin biomimetic and highly bioactive coating. There was, however, direct bone apposition onto and deep into the open structure of the exposed titanium plasma-sprayed layer, without a fibrous interface (Figs $2 \mathrm{c}$ and $3 \mathrm{~b}$ ).

Histological slides did not reveal any toxic effect of the coating or the titanium plasma-sprayed substrate material, nor any inflammatory reaction or histiocytic proliferation, as would have occurred with polyethylene particles. There were no signs of such particles, metal debris or coating delamination. Furthermore, there was no fibrosis or osteolysis. These observations suggested a good 'sealing' effect of the BONITHA coating. Surprisingly, in the infected cases ( 2 and 3 ) there were no identified neutrophil polymorphonuclear or lymphocytic tissue reactions at the bone-implant interface. There was no osteonecrosis or increased osteoclastic activity, nor was there any fibrous coupling between the implant and host bone. In these infected cases it was also necessary to perform an extended trochanteric osteotomy to extract the stem. Thus, it seems that a deep infection does not severely compromise the process of osseo-integration.

In contrast to retrieval reports of other proximally or entirely HA-coated stems, ${ }^{9,24,34}$ which showed signs of progressive osseo-integration in distal Gruen zones 2 to 6 and 3 to 5 , our material did not show any unintended bone apposition, either macro- or microscopically, in the nonHA-coated stem areas (Fig. 2d).

As these were not post-mortem retrievals, instead of collecting the entire femur with the stem, most of the bone had to be separated from the stem to extract it. Therefore, quantitative histomorphometry, expressed as the percentage of bone-implant length contact and bone area density, was calculated in areas where bone came with the explant (referred to as 'relevant areas of interest'), in order to make comparisons with other published post-mortem retrieval reports. Otherwise, quantitative results would be extremely underestimated as a result of the extraction procedure. The division of these results over the entire implant surface, as if it were a post-mortem retrieval, is called the 'mean area of interest' (Table II).

In case 1 , after survival of only three weeks, $26.5 \%$ direct bone-implant contact was already seen in zone $1 \mathrm{~A}$ to $7 \mathrm{~A}$ in that part macroscopically covered with bone and $21.5 \%$ over the entire zone, illustrating the strong osteoconductive character of the BONIT-HA coating. The bone density percentage in this zone was $24.6 \%$ (mean $6.4 \%$ ). For case 2 , the bone implant contact percentage was between $33.4 \%$ and $79.1 \%$ in the relevant area of investigation (mean $51.7 \%)$ and the bone density percentage varied between $16.3 \%$ and $39.0 \%$ (mean $27.2 \%$ ). In case 3 the bone implant contact percentage varied between $51.2 \%$ and $83.5 \%$ (mean $68.1 \%$ ) and the bone density percentage between $26.0 \%$ and $39.3 \%$ (mean $32.5 \%$ ). Considering the impressive amount of bone attached to the explant, and that case 4 had the longest survival of all the retrievals, the relatively low percentage of bone implant contact $(22.3 \%$ (SD 0.3)) in the relevant area of investigation and $14.7 \%$ overall in the metaphyseal area, was less than might be expected. However, these numbers are an underestimation because, judging from its contour, the bone seemed initially to have been in close contact with the implant over a larger area, and a thin gap without fibrous tissue was believed to be a consequence of bone detachment caused by the retrieval process (Fig. 2f).

On SEM analysis there were clear signs of direct bonetitanium plasma-sprayed coating contact, confirming the histological findings (Fig. 3) with bone trabeculae spread over the titanium plasma-sprayed layer without a fibrous interface. Complete resorption of the BONIT-HA coating was seen, which was apparently not detrimental to boneimplant coupling.

\section{Discussion}

This is the first retrieval study to show that the high bioactivity of the BONIT-HA coating is capable of fast and extensive bone ingrowth, both qualitatively and quantitatively, deep into the open surface texture of the Symax stem. In spite of the inherent rapid remodelling of the coating, both histologically and on SEM, there is a high degree of 


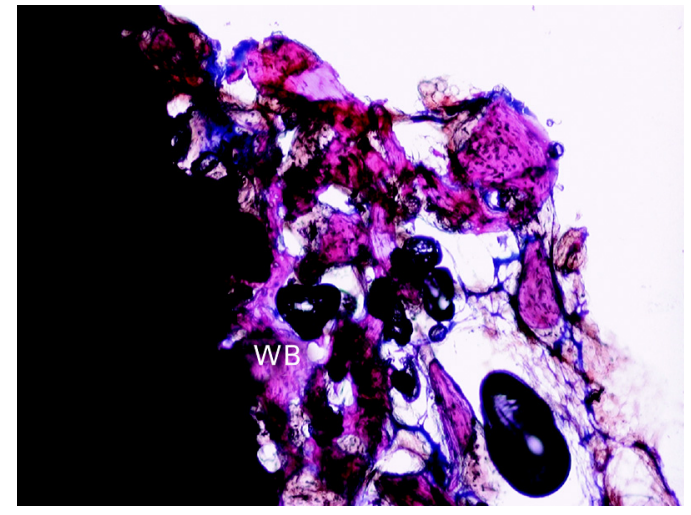

Fig. 2a

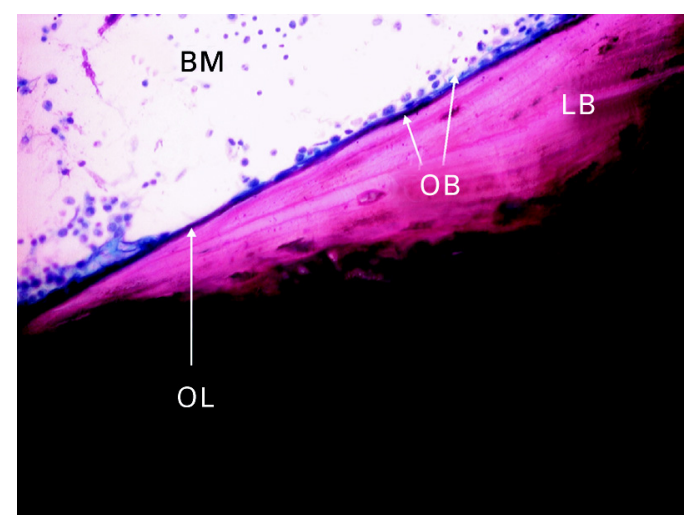

Fig. 2c

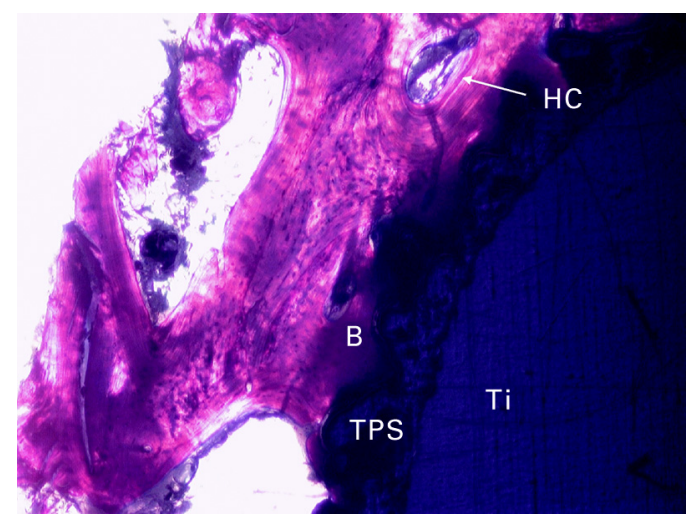

Fig. $2 \mathrm{e}$

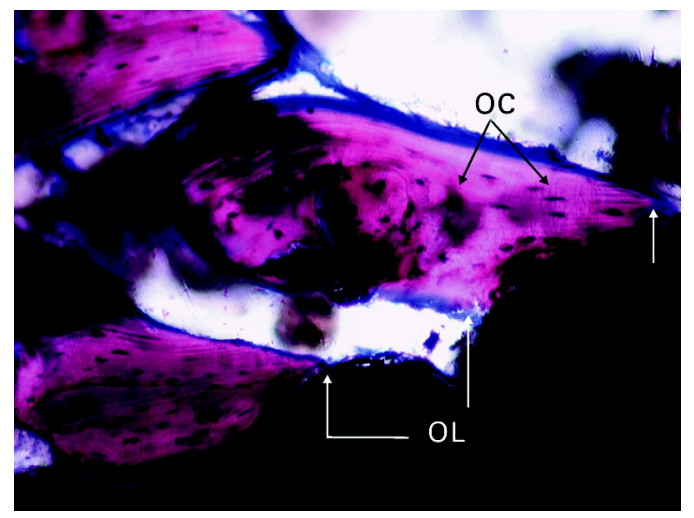

Fig. $2 b$

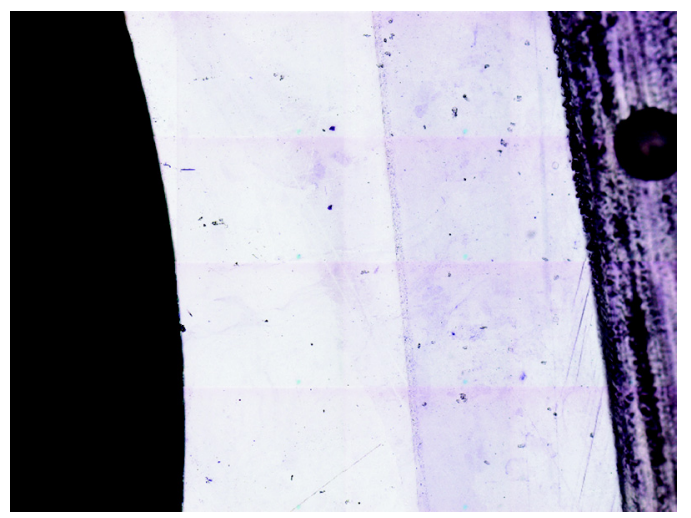

Fig. 2d

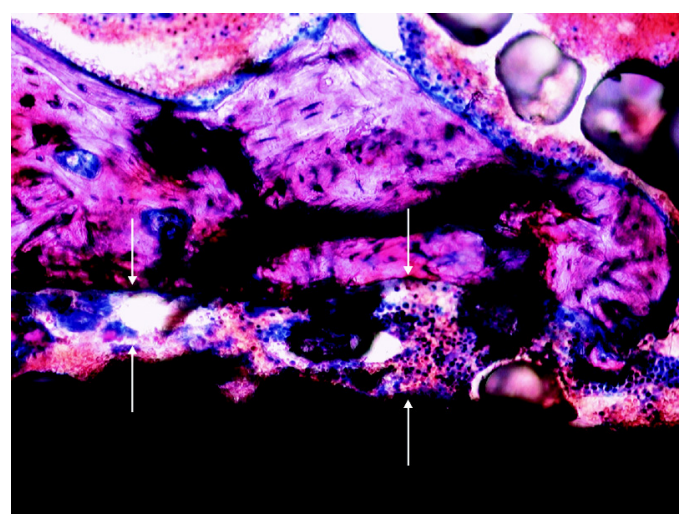

Fig. $2 f$

Histological photomicrographs of cases 1 to 4 . Figure $2 a$ - case 1, showing immature woven bone (WB) in good contact with the implant after only three weeks, as well as crushed bone with artefacts due to the retrieval procedure. No hydroxyapatite coating was identified after this survival period. Figures $2 \mathrm{~b}$ and $2 \mathrm{c}$ - cases 2 and 3, respectively, showing extensive parts of the surface of the implant covered with mature lamellar and actively remodelled bone (LB). There was consistently good osseous anchorage of the implant, with lamellar bone attachment on metal surface (in black), and in continuity with the surrounding trabecular bone ( $b$ and c). Consistently physiologically normal bone marrow (BM) and osteocytes (OC) were seen (b). No signs of inflammation were observed. The osteoid line (OL, b and c) with osteoblasts (OB) in (c), in close contact with the titanium plasma-sprayed layer (TPS), as a sign of active bone generation (c). Figure $2 \mathrm{~d}-\mathrm{case} 2$, showing sections with a smooth surface and no bone or fibrous tissue at distal sites (Gruen zones 2 and 6 and 3 and 5). This was seen in all other cases as well. Figure $2 \mathrm{e}$ - case 3, showing the development of Haversian canals (HC; white arrow), possibly reflecting biomechanically driven corticalisation, a sign of strain-adaptive bone remodelling ( $B$, bone). This was also seen in cases 2 and 4 . Figure $2 f-c a s e 4$, showing detachment of bone (arrows), originally in direct contact with the implant (judging from identical contours of the bone implant surface) but separated by the retrieval procedure. This may lead to underestimation of bone-implant contact in histomorphometry.

sealing of the bone-implant interface, with no negative effect on the short-term bone anchorage of the implant. This supports the expectation that the rough and porous surface texture of the biocompatible titanium plasmasprayed layer and design of the Symax for optimal fit and fill will be able to maintain long-term osseo-integration and 
Table II. Histomorphometric results: the percentage of bone to implant contact (BIC\%) and bone density (BD\%) according to relevant and mean areas of interest

\begin{tabular}{|c|c|c|c|c|c|c|c|c|}
\hline \multirow[b]{2}{*}{ Survival } & \multicolumn{2}{|c|}{ Case 1 (3/4 mnth) } & \multicolumn{2}{|c|}{ Case 2 (9 mths) } & \multicolumn{2}{|c|}{ Case 3 (13 mths) } & \multicolumn{2}{|c|}{ Case 4 (32 mths) } \\
\hline & Relevant aoi* & Mean aoi ${ }^{*}$ & Relev & Mean aoi & Relev & Mear & Relev & Mean aoi \\
\hline \multicolumn{9}{|l|}{$\mathrm{BIC} \%$} \\
\hline $1 \mathrm{~A}$ to $7 \mathrm{~A}$ & 26.5 & 21.5 & 42.7 & 16.0 & 51.2 & 17.7 & 22.5 & 18.7 \\
\hline $1 \mathrm{~B}$ to $7 \mathrm{~B}$ & n.a. ${ }^{\dagger}$ & n.a. & 33.4 & 21.4 & 69.7 & 28.6 & 22.6 & 18.3 \\
\hline $1 \mathrm{C}$ to $7 \mathrm{~B}$ & n.a. & n.a. & 79.1 & 40.4 & 83.5 & 48.0 & 21.8 & 7.1 \\
\hline Metaphyseal mean & n.a. & n.a. & 51.7 & 25.9 & 68.1 & 31.5 & 22.3 & 14.7 \\
\hline SD & n.a. & n.a. & 19.7 & - & 13.2 & 12.5 & 0.3 & - \\
\hline 2 to 6 & n.a. & n.a. & 0.0 & 0.0 & n.a. & n.a. & 0.0 & 0.0 \\
\hline 3 to 5 & n.a. & n.a. & 0.0 & 0.0 & n.a. & n.a. & 0.0 & 0.0 \\
\hline Diaphyseal mean & n.a. & n.a. & 0.0 & 0.0 & n.a. & n.a. & 0.0 & 0.0 \\
\hline SD & n.a. & n.a. & 0.0 & 0.0 & n.a. & n.a. & 0.0 & 0.0 \\
\hline \multicolumn{9}{|l|}{$\mathrm{BD} \%$} \\
\hline $1 \mathrm{~A}$ to $7 \mathrm{~A}$ & 24.6 & 6.4 & 26.5 & 7.2 & 39.3 & 10.4 & 23.9 & 10.5 \\
\hline $1 \mathrm{~B}$ to $7 \mathrm{~B}$ & n.a. & n.a. & 16.3 & 5.9 & 26.0 & 9.3 & 41.1 & 14.8 \\
\hline $1 \mathrm{C}$ to $7 \mathrm{~B}$ & n.a. & n.a. & 39.0 & 16.4 & 32.2 & 19.3 & 1.6 & 0.4 \\
\hline Metaphyseal mean & n.a. & n.a. & 27.2 & 9.9 & 32.5 & 13.0 & 22.2 & 8.6 \\
\hline SD & n.a. & n.a. & 9.3 & - & 5.5 & 4.5 & 16.2 & - \\
\hline 2 to 6 & n.a. & n.a. & 0.0 & 0.0 & n.a. & n.a. & 0.0 & 0.0 \\
\hline 3 to 5 & n.a. & n.a. & 0.0 & 0.0 & n.a. & n.a. & 0.0 & 0.0 \\
\hline Diaphyseal mean & n.a. & n.a. & 0.0 & 0.0 & n.a. & n.a. & 0.0 & 0.0 \\
\hline SD & n.a. & n.a. & 0.0 & 0.0 & n.a. & n.a. & 0.0 & 0.0 \\
\hline
\end{tabular}

The values for the stem surface with bone still attached (relevant area of investigation) are averaged over the entire surface (mean investigation), the value of which should be considered as an underestimation compared to post-mortem retrievals. The values highlighted in bold represent the areas with macroscopic bone attached, those highlighted in italics represent the mean over the entire metaphyseal part of this area

* aoi, area of investigation

† n.a., not analysed

implant stability. We found no adverse effects or signs of local intolerance on the coating, nor any loose particles from the BONIT-HA coating, either in isolation or phagocytosed at the interfaces or in the bone attached to the explants. The study demonstrates that the DOTIZE treatment can prevent bone apposition and osseo-integration at the distal part of the stem, creating optimal stress transfer characteristics to the bone and thereby reducing stress shielding of the proximal femur.

The debate on HA coatings focuses mainly on three controversies: first, should coatings be highly bioactive and hence more resorbable, or should they be stable to enhance bonding more permanently? ${ }^{35-38}$ Secondly, does HA resorption affect the strength of bonding between implant and bone ${ }^{16,39,40}$ Thirdly, can coatings be thin, or should they be thicker?

Although stable coatings may reinforce bonding for longer, they are intrinsically less bioactive. More bioactive coatings, however, deliver a high local source of calcium and phosphate ions for rapid-contact osteogenesis, and therefore tend to disintegrate faster. ${ }^{21,41,42}$ The resorbability of coatings is determined by chemical factors $(\mathrm{pH}$, crystal composition) and material structure (surface area, porosity), which also influence adhesion and the activity of precursor osteoblasts. ${ }^{24,43-48}$ Resorption of the coating depends strongly on osteoclastic activity, which is ruled by these physicochemical characteristics. ${ }^{49-51}$ Research on newer coatings should therefore be directed towards finding combinations of coatings with sufficient bioactivity to encourage bone ingrowth, but which do not dissolve before mechanical stability has been achieved through ingrowth.

Degradation of HA coatings forms an essential part in the remodelling of the bone-implant interface. Thinner coatings (i.e., BONIT-HA $2 \mu \mathrm{m}$ to $20 \mu \mathrm{m}$ ) applied to metallic substrates achieve the strength properties of the underlying material, resulting in a better mechanical stability of the coating on the implant. Through transformation by osteoclastic activity, they can prevent heavy burdens of particulate material. Thicker 'first-generation' coatings, however (Furlong, approximately $200 \mu \mathrm{m}$ thick), and to a lesser extent 'second-generation' intermediate coatings (Omnifit, $60 \mu \mathrm{m}$ and ABG, $70 \mu \mathrm{m}$ ) because of their brittleness, may delaminate and theoretically release particulate apatite material with subsequent 'third-body wear' and osteolysis. ${ }^{16,17}$ That this has not been shown to be a clinical problem is possibly related to the sealing capacity of the implant-bone interface through early osseointegration. ${ }^{52,53}$ During this process, particularly in thin bioactive coatings, degradation of the calcium phosphate layer does not seem to initiate histiocyte or giant cell proliferation and 
wear-induced osteolysis as polyethylene particles do. This is probably because this HA does not behave like an abrasive or foreign-body particle, but as a natural calcium phosphate graft, which is more easily remodelled by osteoclasts or phagocytosed by macrophages and dissolved within their acid environment. For these and other reasons, therefore, it seems advantageous to apply biomimetic instead of conventional plasma-spray HA coatings. Processing is possible under better control of the physicochemical environment (neutral $\mathrm{pH}$, low-/body-temperature), with improved regulation of crystallinity and $\mathrm{Ca} / \mathrm{P}$ ratio, along with the rate of bioactivity and degradation. Thinner coatings can then be applied with a lower theoretical chance of delamination and a better and deeper coating of the threedimensional open surface texture of the implant. Depending on the surface characteristics of the implant (roughness and porosity), there will be improved bone-implant anchorage and long-term osseo-integration, even after the HA coating has disappeared. Faster osseo-integration will support early biological stability of the implant, thereby preventing its migration and the development of a fibrous and unstable interface. This may be particularly useful in patients with poor bone quality, such as those with osteoporosis. In the long term, these deposition techniques may create more complete sealing of the bone-implant interface as a protection against particle ingress and subsequent wear-induced peri-prosthetic osteolysis.

From other proximally or completely coated titanium stems it is known that the initial proximal osseo-integration is to some extent followed by progressive distal osseointegration. ${ }^{54,55}$ This will cause stress shielding at the femoral metaphysis, with bone resorption in Gruen zones 1 and 7 , as recognised radiologically and from peri-prosthetic densitometry (DEXA). This potentially detrimental effect of distal stem integration may be prevented by the DOTIZE treatment, our retrieval results of which show complete absence of distal bone apposition (Fig. 2d).

The histomorphometric results of BONIT-HA coating compared with plasma-sprayed coatings show good boneimplant contact and bone density percentage. In a postmortem retrieval study of femoral implants, Porter et $\mathrm{al}^{10}$ compared femoral stems coated with plasma-sprayed HA (Bimetric; Biomet, Bridgend, United Kingdom) with implants of the same design but showing exposed titanium after degradation of HA, and porous-coated implants without HA. The bone-implant contact percentage in these groups was between $40 \%$ and $50 \%$ (HA coating still present), $24 \%$ (SD 5) (exposed titanium after HA degradation) and $21 \%$ (SD 14) (non-HA-coated porous stems), suggesting a decline in bone bonding with loss of HA. The porouscoated stems showed large areas with a fibrous tissue interface and barely adherent bone, with trabecular bridges to surrounding cancellous host bone.

Tonino et $\mathrm{al}^{34}$ showed that the mean bone ingrowth in Gruen zones 1 and 7 of retrieved femora with the plasmasprayed HA-coated ABG stems (Stryker, Newbury, United

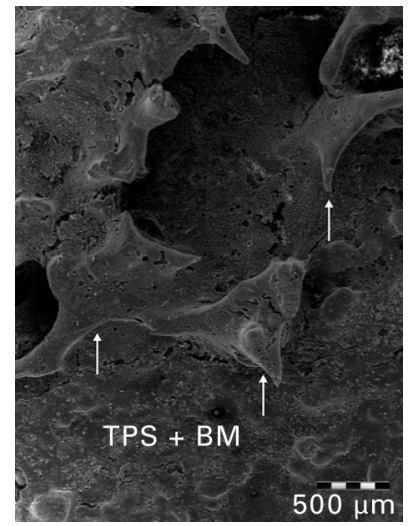

Fig. 3a

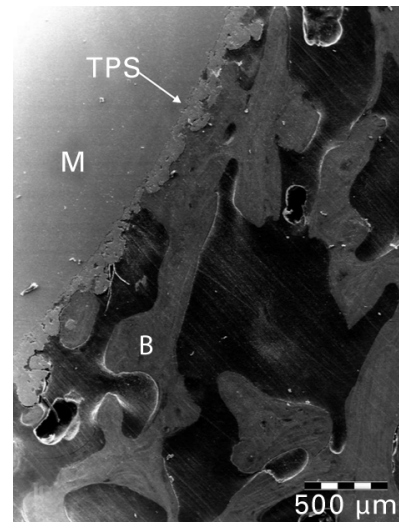

Fig. 3b
Scanning electron microscopy photographs of cross-sections of the implant in a) case 2, showing three-dimensional contour of trabecular bone (arrows) in contact with the titanium plasma-sprayed surface (TPS) covered with bone marrow (BM), and b) case 4, showing metal (M), TPS layer and direct ingrowth of bone trabecula (B) into the surface of the implant without a fibrous tissue interface.

Kingdom) varied between $22 \%$ and $56 \%$ of the total surface. Coathup et $\mathrm{a}^{11}$ compared bone ingrowth and attachment in post mortem retrievals of one hip design (Bimetric; Biomet), proximally coated with either a plasma-sprayed HA porous coating, a plain plasma-sprayed porous coating or only grit-blasted (Interlok; Biomet). Bone attachment was respectively $37.3 \%$ (SD 2.5) (porous HA), $18.9 \%$ (SD 2.0) (plain porous) and 22.6\% (SD 3.7) (Interlok). Bone ingrowth in the pores was $29.1 \%$ (SD 2.0 ) versus $21.8 \%$ (SD 2.1) (Interlok not mentioned). Bauer et $\mathrm{al}^{9}$ assessed the amount of bone apposition on post-mortem Omnifit retrievals (Osteonics, Allendale, New Jersey) with proximal plasma-sprayed HA coating and found that it varied between $32 \%$ and $78 \%$. For comparison, Cook et $\mathrm{al}^{56}$ quantified bone ingrowth on porous-coated hip stems of different designs and saw bone growth into the available pore volume of $<10 \%$ in all cases, whereas the rest of the stem surfaces showed fibrous encapsulation.

All these results involve post-mortem retrievals in which a more representative osseo-integration for a particular stem design in all Gruen zones could be analysed without disruption by the extraction procedure. For the relatively new Symax stem for which there are as yet no post-mortem retrievals, we are restricted to 'relevant areas of interest'. Otherwise, the positive quantitative results of the Symax would be extremely underestimated because of the extraction procedure.

Although the amount of bone-implant contact and bone density within the relevant area of investigation is promising, the sample size of only four cases greatly limits more generalised conclusions. Further investigations of retrieved cases evaluating long-term osseo-integration are recommended. 
Although none of the authors has received or will receive benefits for persona or professional use from a commercial party related directly or indirectly to the subject of this article, benefits have been or will be received but will be directed solely to a research fund, foundation, educational institution, or the other nonprofit organisation with which one or more of the authors are associated.

\section{References}

1. Geesink RG, de Groot K, Klein CP. Bonding of bone to apatite-coated implants. J Bone Joint Surg [Br] 1988;70-B:17-22.

2. Søballe K. Hydroxyapatite ceramic coating for bone implant fixation: mechanical and histological studies in dogs. Acta Orthop Scand Supp/ 1993;255:1-58.

3. Cook SD, Thomas KA, Dalton JE, et al. Hydroxylapatite coating of porous implants improves bone ingrowth and interface attachment strength. J Biomed Mater Res 1992;26:989-1001.

4. D'Antonio JA, Capello WN, Crothers OD, Jaffe WL, Manley MT. Early clinical experience with hydroxyapatite-coated femoral implants. J Bone Joint Surg [Am] 1992:74-A:995-1008.

5. Tonino AJ, Romanini L, Rossi P, et al. Hydroxyapatite-coated hip prostheses: early results from an international study. Clin Orthop 1995;312:211-25.

6. Geesink RG, Hoefnagels NH. Six-year results of hydroxyapatite-coated total hip replacement. J Bone Joint Surg [Br] 1995;77-B:534-47.

7. Capello WN, D'Antonio JA, Jaffe WL, et al. Hydroxyapatite-coated femoral components: 15-year minimum followup. Clin Orthop 2006;453:75-80.

8. Havelin LI, Engesaeter LB, Espehaug B, et al. The Norwegian Arthroplasty Register: 11 years and 73,000 arthroplasties. Acta Orthop Scand 2000;71:337-53.

9. Bauer TW, Geesink RG, Zimmerman R, McMahon JT. Hydroxyapatite-coated femoral stems: histological analysis of components retrieved at autopsy. J Bone Joint Surg [Am] 1991;73-A:1439-52.

10. Porter $\mathbf{A E}$, Taak $\mathbf{P}$, Hobbs $\mathbf{L W}$, et al. Bone bonding to hydroxyapatite and titanium surfaces on femoral stems retrieved from human subjects at autopsy. Biomaterials 2004;25:5199-208.

11. Coathup MJ, Blunn GW, Flynn N, Williams C, Thomas NP. A comparison of bone remodelling around hydroxyapatite-coated, porous-coated and grit-blasted hip replacements retrieved at post-mortem. J Bone Joint Surg [Br] 2001;83-B:118-23.

12. Yankee SJ, Pletka BJ, Luckey HA, Johnson WA. Processes for fabricating hydroxyapatite coatings for biomedical applications: thermal spray research and application. In: Procs National Thermal Spray Conference, 1990:433-8.

13. Donath K. Reactions of tissue to calcium phosphate ceramics. In: Heinke G, ed. Osseo-integrated implants 2: implants in oral and ENT surgery. Boca Raton: CRC Press, 1990:99-125.

14. Wheeler SL. Eight-year clinical retrospective study of titanium plasma-sprayed and hydroxyapatite-coated cylinder implants. Int J Oral Maxillofac Implants 1996;11:340

15. Harada Y, Wang JT, Doppalapudi VA, et al. Differential effects of different forms of hydroxyapatite and hydroxyapatite/tricalcium phosphate particulates on human monocyte/macrophages in vitro. J Biomed Mater Res 1996;31:19-26.

16. Bloebaum RD, Beeks D, Dorr LD, et al. Complications with hydroxyapatite particulate separation in total hip arthroplasty. Clin Orthop 1994;298:19-26.

17. Morscher EW, Hefti A, Aebi U. Severe osteolysis after third-body wear due to hydroxyapatite particles from acetabular cup coating. J Bone Joint Surg [Br] 1998;80B:267-72.

18. Kokubo T, Kushitani H, Sakka S, Kitsugi T, Yamamuro T. Solutions able to reproduce in vivo surface-structure changes in bioactive glass-ceramic A-W. J Biomed Mater Res 1990;24:721-34.

19. Barrère F, Layrolle P, Van Blitterswijk CA, De Groot K. Biomimetic coatings on titanium: a crystal growth study of octacalcium phosphate. J Mater Sci Mater Med 2001;12:529-34.

20. Barrére F, Layrolle P, van Blitterswijk CA, de Groot $K$. Biomimetic calcium phosphate coatings on Ti6A14V: a crystal growth study of octacalcium phosphate and inhibition by $\mathrm{Mg}^{2+}$ and $\mathrm{HCO}_{3}^{-}$. Bone 1999;25(Suppl):107-111.

21. Szmukler-Moncler S, Perrin D, Ahossi V, Pointaire PL. Evaluation of BONIT, fully resorbable $\mathrm{CaP}$ coating obtained by electrochemical deposition, after 6 weeks of healing: a pilot study in the pig maxilla. Bioceramics 2001;13:395-8.

22. Becker $\mathbf{P}$, Zeggel $\mathbf{P}$, Lüthen $\mathbf{F}$, et al. Resorbable calcium phosphate composite coatings. Bioceramics 2002;14:653-6.

23. Barrère F. Biomimetic calcium phosphate coatings: physiochemistry and biological activity. Thesis, 2002, University of Twente, Enschede, The Netherlands.
24. Becker P, Neumann NG, Nebe B, Lüthen F, Rychly J. Cellular investigations on electrochemically deposited calcium phosphate composites. J Mater Sci Mater Med 2004;15:437-40

25. ASTM International. Standards worldwide. http://www.astm.org (date last accessed 20 April 2011).

26. International Organization for Standardization (ISO). ISO standards. http:// www.iso.org (date last accessed 20 April 2011).

27. Cigada A, Cabrini M, Pedeferri P. Increasing of the corrosion resistance of the Ti6A14V alloy by high thickness anodic oxidation. J Mater Sci Mater Med 1992;3:40812.

28. Becker P, Baumann A, Lüthen $\mathbf{F}$, et al. Spark anodization on titanium and titanium alloys. Procs 10th World Conference on Titanium 2003:3339-44.

29. Joschek S, Nies B, Krotz R, Göferich A. Chemical and physicochemical characterization of porous hydroxyapatite ceramics made of natural bone. Biomaterials 2000;21:1645-58.

30. Redepenning J, Schlessinger T, Burnham S, Lippiello L, Miyano J. Characterization of electrolytically prepared brushite and hydroxyapatite coatings on orthopedic alloys. J Biomed Mater Res 1996;30:287-94.

31. Gruen TA, McNeice GM, Amstutz HC. "Modes of failure" of cemented stem-type femoral components: a radiographic analysis of loosening. Clin Orthop 1979;141:17-

32. Donath K, Breuner G. A method for the study of undecalcified bones and teeth with attached soft tissues: the Säge-Schliff (sawing and grinding) technique. J Oral Pathol 1982;11:318-26.

33. Zubery Y, Goldlust A, Alves A, Nir E. Ossification of a novel cross-linked porcine collagen barrier in guided bone regeneration in dogs. J Periodonto/ 2007:78:112-21.

34. Tonino AJ, Thèrin M, Doyle C. Hydroxyapatite-coated femoral stems: histology and histomorphometry around five components retrieved at post mortem. J Bone Joint Surg [Br] 1999;81-B:148-54.

35. Klein CP, Wolke JG, de Blieck-Hogervorst JM, de Groot K. Calcium phosphate plasma-sprayed coatings and their stability: an in vivo study. J Biomed Mater Res 1994;28:909-17

36. Maxian SH, Zawadsky JP, Dunn MG. Effect of $\mathrm{Ca} / \mathrm{P}$ coating resorption and surgical fit on the bone/implant interface. J Biomed Mater Res 1994;28:1311-19.

37. Overgaard S, Bromose U, Lind M, Bünger C, Søballe K. The influence of crystallinity of the hydroxyapatite coating on the fixation of implants: mechanical and histomorphometric results. J Bone Joint Surg [Br] 1999;81-B:725-31

38. Chou L, Marek B, Wagner WR. Effects of hydroxylapatite coating crystallinity on biosolubility, cell attachment efficiency and proliferation in vitro. Biomaterials 1999;20:977-85

39. Bauer TW. Hydroxyapatite: coating controversies. Orthopedics 1995;18:885-8.

40. Søballe K, Overgaard S. The current status of hydroxyapatite coating of prostheses. J Bone Joint Surg [Br] 1996;78-B:689-91.

41. Clèries L, Fernández-Pradas JM, Sardin G, Morenza JL. Dissolution behaviour of calcium phosphate coatings obtained by laser ablation. Biomaterials 1998;19:1483-7.

42. Klein CP, de Blieck-Hogervorst JM, Wolke JG, de Groot K. Studies of the solubility of different calcium phosphate ceramic particles in vitro. Biomaterials 1990;11:509-12

43. Klein CP, Driessen AA, de Groot $K$, van den Hooff A. Biodegradation behavior of various calcium phosphate materials in bone tissue. J Biomed Mater Res 1983; $17: 769-84$

44. Boyan BD, Hummert TW, Dean DD, Schwartz Z. Role of material surfaces in regulating bone and cartilage cell response. Biomaterials 1996;17:137-46.

45. Redey SA, Nardin M, Bernache-Assolant D, et al. Behavior of human osteoblastic cells on stoichiometric hydroxyapate and type A carbonate apatite: role of surface energy. J Biomed Mater Res 2000;50:353-64.

46. Lampin M, Warocquier-Clérout, Legris C, Degrange M, Sigot-Luizart MF. Correlation between substratum roughness and wettability, cell adhesion, and cell migration. J Biomed Mater Res 1997;36:99-108.

47. Anselme K. Osteoblast adhesion on biomaterials. Biomaterials 2000;21:667-81.

48. Ong JL, Hoppe CA, Cardenas HL, et al. Osteoblast precursor cell activity on HA surfaces of different treatments. J Biomed Mater Res 1998;39:176-83.

49. Leeuwenburgh $\mathbf{S}$, Layrolle $\mathbf{P}$, Barrère $\mathbf{F}$, et al. Osteoclastic resorption of biomimetic calcium phosphate coatings in vitro. J Biomed Mater Res 2001;56:208-15.

50. Doi Y, Iwanaga H, Shibutani T, Moriwaki Y, Iwayama Y. Osteoclastic responses to various calcium phosphates in cell cultures. J Biomed Mater Res 1999;47:424-33. 
51. Yamada S, Heymann D, Bouler JM, Daculsi G. Osteoclastic resorption of calcium phosphate ceramics with different hydroxyapatite/beta-tricalcium phosphate ratios. Biomaterials 1997;18:1037-41.

52. Bauer TW, Taylor SK, Jiang M, Medendorp SV. An indirect comparison of thirdbody wear in retrieved hydroxyapatite-coated, porous, and cemented femoral components. Clin Orthop 1994;298:11-18.

53. Rahbek 0, Overgaard S, Lind $\mathbf{M}$, et al. Sealing effect of hydroxyapatite coating on peri-implant migration of particles: an experimental study in dogs. J Bone Joint Surg [Br] 2001;83-B:441-7.
54. Engh CA, Bobyn JD, Glassman AH. Porous-coated hip replacement: the factors governing bone ingrowth, stress shielding, and clinical results. J Bone Joint Surg [Br] 1987;69-B:45-55

55. Engh CA, Bobyn JD. The influence of stem size and extent of porous coating on femoral bone resorption after primary cementless hip arthroplasty. Clin Orthop 1988;231:7-28

56. Cook SD, Barrack RL, Thomas KA, Haddad RJ Jr. Quantitative analysis of tissue growth into human porous total hip components. J Arthroplasty 1988;3:249-62. 